\title{
PerCursos
}

\section{Filosofias indígenas: fractalidade como ferramenta de conhecimentos tradicionais}

\begin{abstract}
Resumo
O pensamento eurocentrado, que possui base dualista da balança e dois pesos, na lógica aristotélica e na Geometria Euclidiana e Cartesiana, foi fortemente criticado por intelectuais influenciados pelas Filosofias não eurocentradas. Contudo, as influências de Filosofias Indígenas presentes no Pragmatismo e na Filosofia do Processo que influenciaram Felix Guattari e Gilles Deleuze, estes influenciados por Pierre Clastres, que etnografou sociedades Indígenas contra o Estado centralizador tão caro à Europa. Tais críticas produziram Isabelle Stengers, Bruno Latour, Tim Ingold que trazem novas perspectivas à Antropologia e à Sociologia, bem como Milton Santos que trouxe uma Geografia nova. Esses movimentos nos auxiliaram a delinear a proposta de Apensamento, como organizador da multiplicidade composta por seres com diversidade multiescalar e fractal, comum nas Filosofias Indígenas, que podemos utilizar como ferramenta na decolonização do pensar eurocentrado.
\end{abstract}

Palavras-chave: Filosofia; indígenas; fractais; apensamento.
Orivaldo Nunes Junior

Bacharel em Filosofia pela Universidade Federal de Santa Catarina - UFSC. Mestre em Educação pela Universidade Federal de Santa Catarina - UFSC. Doutorando em Planejamento Territorial e Desenvolvimento Socioambiental na Universidade do Estado de Santa Catarina UDESC. Brasil nunonunes3@gmail.com

\section{Para citar este artigo:}

NUNES, Orivaldo Jr.. Filosofias indígenas: fractalidade como ferramenta de conhecimentos tradicionais.

PerCursos, Florianópolis, v. 22, n.48, p. 174 - 207, jan./abr. 2021. 


\title{
Indigenous philosophies: fractality as a tool of traditional knowledge
}

\begin{abstract}
The Eurocentric thought, with its dualistic basis of the scale and two weights, in Aristotelian logic and Euclidean and Cartesian Geometry, was strongly criticized by intellectuals influenced by non-Eurocentric philosophies. However, the influences of Indigenous philosophies present in Pragmatism and Process Philosophy that influenced Felix Guattari and Gilles Deleuze, these influenced by Pierre Clastres, who ethnographed Indigenous societies against the centralizing State so dear to Europe. Such criticism produced Isabelle Stengers, Bruno Latour, Tim Ingold, who bring new perspectives to Anthropology and Sociology, and Milton Santos, who brought a new Geography. These movements helped us outline the Appendage proposal, as an organizer of the multiplicity comprised of beings with multiscalar and fractal diversity, common in Indigenous Philosophies, which we can use as a tool in the decolonization of Eurocentered thinking.
\end{abstract}

Keywords: Philosophy; indigenous; fractal; attachinking. 


\section{Introdução}

A Filosofia, como busca pela sabedoria, tem origem mediterrânea, mais precisamente entre Egito e Grécia no período clássico (séculos V e VI a.C). Não sem motivos, o pensamento filosófico surgiu com a necessidade social de unificar cidadesestado para enfrentamento dos inimigos vizinhos e sua organização social imperial, os aquemênidas e persas. Contudo, como unificar diferentes formas de pensamento? A solução foi buscar a verdade maior e mais duradoura entre todas as tradições. O Filósofo, traduzido como "amigo do saber", era o guerreiro na luta pela unificação, buscando padrões, perfis comuns entre as diferentes culturas, com objetivo de estruturar logicamente e retirar as contradições. O método utilizado nesta busca foi o pensar, que possui o conceito de "pesar" em sua etimologia, oriundo na metáfora de colocar dois pesos sobre um ponto fixo, do latim bi (dois) lanx (pratos), representado pela "balança". Conforme Aristóteles (384 a.C - 322 a.C), em sua obra "Tópicos dos argumentos sofísticos",

Sempre que duas coisas se assemelhem muito entre si e não podemos ver nenhuma superioridade numa delas sobre a outra, devemos examinálas sob o ponto de vista de suas consequências. Porquanto a que tem como consequência o bem maior é a mais desejável; ou, se as consequências forem más, será mais desejável a que for seguida de um mal menor. Com efeito, embora ambas sejam desejáveis, pode haver entre elas alguma consequência desagradável que faça pender a balança. (ARISTÓTELES; PESSANHA, 1987, p. 83)

A atividade filosófica de "pesar" ideias usa o raciocínio como ferramenta que, conforme Aristóteles e Pessanha (1987, p. 33), "é um argumento em que, estabelecidas certas coisas, outras coisas diferentes se deduzem necessariamente das primeiras". Razão, do latim rácio (parte), tem origem etimológica em “separação em partes” que, na arte de pensar/pesar, se transforma em observar entre duas premissas qual a verdadeira e primeira.

Ilya Prigogine e Isabelle Stengers, no livro A nova aliança (1991), afirmam em uma de suas teses centrais, que "os problemas que marcam uma cultura podem ter uma 
influência sobre o conteúdo e o desenvolvimento das teorias científicas" (PRIGOGINE; STENGERS, 1991, p. 8). As partes separadas formam a dualidade que compõe a verdade única buscada pelos filósofos, e tal estrutura pode ser facilmente encontrada nos mitos dos povos mediterrâneos. Por exemplo, para os gregos, no princípio era o Caos, que se dividiu em duas partes: Urano, o céu; e Gaia, a terra; para os egípcios, Atum se dividiu em Shu, deus do ar, e Tefnut, deusa da chuva, que tiveram dois filhos, Geb, deus da terra e Nut, a deusa do céu; vemos também na doutrina cristã, em que para alcançar o Pai (Deus), deve antes passar pelo Filho (Jesus) e pelo Espírito Santo. Numericamente, seria o 1 (um) que se divide em 2 (dois) e segue a divisão para a multiplicidade. Fazendo o caminho reverso ao da criação mítica, pensadores poderiam ver como óbvia a busca da dualidade dentro da multiplicidade que se apresenta aos sentidos e, a partir de dois polos, encontrar o único.

Figura 1 - Exemplo gráfico da Lógica aristotélica e cartesiana

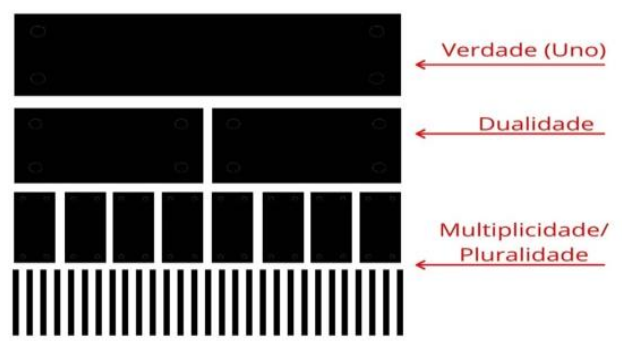

Fonte: Elaborada pelo autor.

Conforme a Figura 1, poderíamos dispor que Aristóteles (2005) propôs método de baixo para cima (da multiplicidade até a verdade). Contudo, o francês René Descartes (1596-1650) (DESCARTES, 1973) revisitou o método aristotélico e propôs analisar (separar) as coisas de cima para baixo e, depois, de baixo para cima (verdade analisada até a multiplicidade de partes e retornar à verdade sintetizando e afastando as contradições). Na geometria, temos a origem dos padrões fundamentados em Euclides de Alexandria (século III a.C) que estabeleceu seu modelo de espaço imutável e simétrico (Figura 2) e que foram seguidos por Aristóteles e Descartes (Figura 3). 
Figura 2 - Geometria Clássica, Euclidiana (600 a.C)

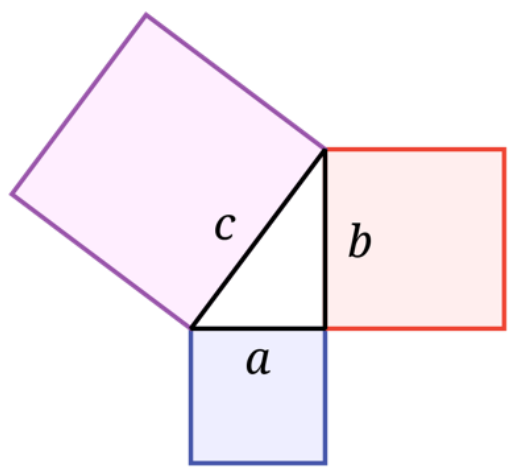

Fonte: Página do verbete no Wikipédia'.
Figura 3 - Geometria Analítica, Cartesiana

(1600)

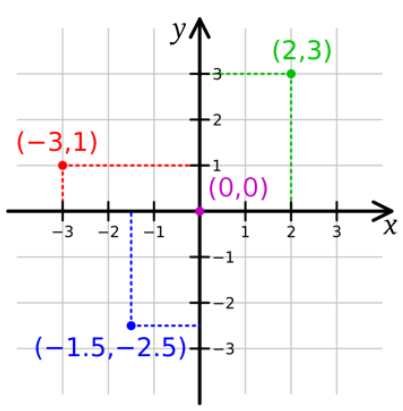

Fonte: Página do verbete no Wikipédia².

Deste modo, o método eurocentrado de alcançar o conhecimento espalhou-se para os demais continentes após o período de colonização de 1492 em diante, com a dominação das Américas pelas “armas, germes e aço" europeias, causando genocídios e epistemicídio de inúmeras populações Indígenas, conforme expôs o biólogo estadunidense Jared Diamond (1997). No entanto, outras formas de buscar o conhecimento, ou ainda, outras epistemologias 3 , de origem não eurocêntricas, podem carregar questões culturais que influenciam sobre suas teorias e práticas, conforme nos ensina Prigogine e Stengers (1991).

Assim, no século XX surgiram críticos ao pensamento eurocentrado e esforços para descolonizar as Ciências, respeitando conhecimentos de Povos Indígenas e Tradicionais. Para tanto, observaremos aqui que as origens das críticas ao eurocentrismo têm fortes influências nas epistemes de Povos Indígenas e, também, em suas formas de buscar o saber, isto é, suas Filosofias.

\footnotetext{
${ }^{1}$ Disponível em: <https://pt.wikipedia.org/wiki/Historia_da_geometria>. Acesso em: 13 abr. 2021.

${ }^{2}$ Disponível em : <https://pt.wikipedia.org/wiki/Geometria_analitica>. Acesso em: 13 abr. 2021.

3 Episteme tem origem etimológica Indoeuropeia de "colocar de pé sobre" algo, referindo-se a uma melhor forma de observar (em http://etimologias.dechile.net/?episteme. Visitado em: fevereiro de 2021).
} 


\section{Críticas ao método científico eurocentrado}

Em uma breve descrição bibliográfica dos debates sobre críticas ao método científico eurocentrado, temos a Filósofa belga Isabelle Stengers (1949-) que apontou a relação nas Ciências do observador (cientista) e do objeto observado (molécula), afirmando que

nada confere à molécula 'em si', independentemente do cientista, o poder de suscitar essas provas das quais ela depende, de impor aos pesquisadores, aos industriais, aos jornais científicos, um interesse sem o qual ela permaneceria uma simples molécula, nua, com papel e possibilidades indeterminados. [...] O cientista é constrangido a se interessar pelo mundo, a transformá-lo, para que este mundo faça existir sua molécula. (STENGERS,1993, p. 138)

O Filósofo francês Bruno Latour (1947-) denunciou a proximidade entre a atividade científica e a atividade política, afirmando que "a ciência é a política praticada por outros meios" (LATOUR, 1997, p. 168). Com isso, faz críticas aos métodos aristotélico e cartesiano que afastam os seres existentes como agentes ativos nos processos científicos - antes considerados apenas como passivos - que Latour os toma como participantes da rede de atores humanos e não humanos que influenciam as definições científicas.

O Antropólogo britânico Tim Ingold (1948-) aprofundou o tema com suas críticas para além da rede, afirmando que esta ainda atuaria conforme o paradigma da materialidade e da forma aristotélica, relatando que

Para criar algo, refletiu Aristóteles, deve-se juntar forma (morphé) e matéria (hyle). Na história subsequente do pensamento ocidental, esse modelo hilemórfico da criação arraigou-se ainda mais, mas também se desequilibrou. A forma passou a ser vista como imposta por um agente com um determinado fim ou objetivo em mente sobre uma matéria passiva e inerte. Quero argumentar aqui que os debates contemporâneos em campos os mais diversos - da antropologia e arqueologia à história da arte e estudos da cultura material - continuam a reproduzir os pressupostos que subjazem ao modelo hilemórfico, ainda que tentem restaurar o equilíbrio entre seus termos. (INGOLD, 2012, p. 26) 
Desse modo, Ingold apontou que seu “objetivo final, por outro lado, é derrubar o próprio modelo, e substituí-lo por uma ontologia que dê primazia aos processos de formação ao invés do produto final, e aos fluxos e transformações dos materiais ao invés dos estados da matéria", (INGOLD, 2012, p. 26). E continua

como a aranha, as vidas das coisas geralmente se estendem ao longo não de uma mas de múltiplas linhas, enredadas no centro mas deixando para trás inúmeras "pontas soltas" nas periferias. (INGOLD, 2012, p. 41)

Assim, cada coisa pode ser vislumbrada, como Latour tem sugerido mais recentemente, no formato de uma estrela "com um centro cercado de muitas linhas que irradiam, com uma multiplicidade de condutores mínimos transmitindo de um lado para o outro." (LATOUR, 2005, p. 177 apud INGOLD, 2012, p. 41)

Não mais um objeto autocontido, a coisa aparece agora como uma teia ramificante de linhas de crescimento. (INGOLD, 2012, p. 41)

Ingold salientou que já os filósofos franceses Gilles Deleuze e Felix Guattari (2004, p. 290), haviam proposto uma imagem "associada por eles a um rizoma" (INGOLD, 2012, p. 41). E afirma o britânico que

Qualquer que seja a imagem escolhida, o crucial é que comecemos pelo caráter fluido do processo vital, onde os limites são sustentados graças ao fluxo de materiais através deles. (INGOLD, 2012, p. 41)

Diante o exposto, diferentemente da Figura 1 que apresenta um exemplo gráfico da lógica aristotélica e cartesiana de buscar em meio à multiplicidade a dualidade com vistas a alcançar a unidade verdadeira, trazemos abaixo as figuras propostas pelos autores vistos acima como representações gráficas de suas Filosofias, como "rizomas" (Figura 4) em Deleuze e Guatarri, "redes" ou "network" (Figura 5) em Latour, ou com "malhas" e "teias" ou "mashwork" (Figura 6) em Ingold4.

\footnotetext{
4 Ingold afirmou que "tomei o termo 'malha' de empréstimo da filosofia do Henri Lefebvre" (1901-1991), Filósofo francês, em LEFEBVRE, H. The production of space. Trans. D. Nicholson-Smith. Oxford: Blackwell, 1991.
} 
Figura 4 - Rizoma (Deleuze e Guatari)

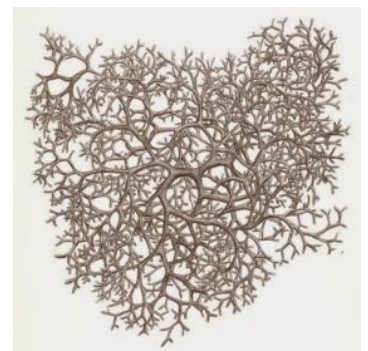

Fonte: Página Filosofia do Design5.
Figura 5 - Rede/Network (Latour)

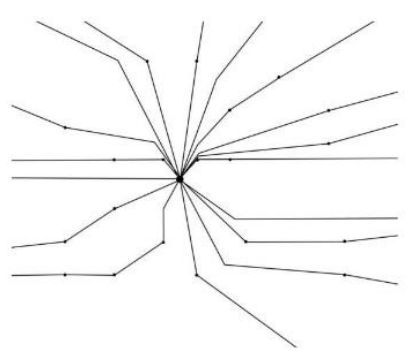

Fonte: ELIAS, 2020, p. 54.
Figura 6 - Malha/Mashwork (Ingold)

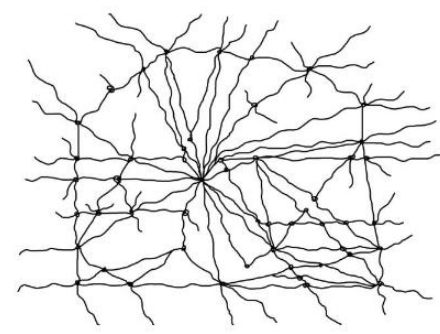

Fonte: ELIAS, 2020, p. 54.

Temos também as críticas do geógrafo brasileiro Milton Santos (1926-2001), que nos chama atenção para a Totalização. Em sua a obra Natureza do Espaço, ele afirmou que

O todo somente pode ser conhecido através do conhecimento das partes e as partes somente podem ser conhecidas através do conhecimento do todo. Essas duas verdades são, porém, parciais. Para alcançar a verdade total, é necessário reconhecer o movimento conjunto do todo e das partes, através do processo de totalização. (SANTOS, M., 2006, p. 77)

Para Milton Santos, a totalização seria "um processo de unificação e de fragmentação e individuação" (2006, p. 14) e, para compreendermos isso, é necessário perceber que Santos, como sua geração de pensadores, viveu sob influência das descobertas no mundo da Física Teórica do alemão Albert Einstein (1879-1955). Como afirma Santos:

Na esteira de Einstein, Minkowski e tantos outros, são muitos a falar na inseparabilidade do tempo e do espaço [...] Insistir no fato de que tempo e espaço reciprocamente se substituem, numa total integração. (SANTOS, M., 2006, p. 32)

\footnotetext{
5 Disponível em: <http://filosofiadodesign.com/wp-content/uploads/2015/10/rizoma-01-297×300.jpg>. Acesso em: 13 abr. 2021.
} 
A guinada filosófica promovida pelas teorias de Einstein, com a Relatividade entre Tempo e Espaço, foi marcante diante do fato que a Teoria Física anteriormente aceita era do inglês Isaac Newton (1643 -1727), que considerava forças separadas, o que Einstein unificou como Espaço-tempo. Santos afirma que

Tempo, espaço e mundo são realidades históricas, que devem ser mutuamente conversíveis, se a nossa preocupação epistemológica é totalizadora. Em qualquer momento, o ponto de partida é a sociedade humana em processo, isto é, realizando-se. Essa realização se dá sobre uma base material: o espaço e seu uso; o tempo e seu uso; a materialidade e suas diversas formas; as ações e suas diversas feições. Assim empiricizamos o tempo, tornando-o material, e desse modo o assimilamos ao espaço, que não existe sem a materialidade. (SANTOS, M., 2006, p. 33)

Milton Santos analisa o tempo a partir da sua escalaridade. Ele afirma que "a escala é um dado temporal e não propriamente espacial; ou, ainda melhor, que a escala varia com o tempo, já que a área de ocorrência é dada pela extensão dos eventos" (SANTOS, M. 2006, p. 99). E como “evento", Milton Santos (2006, p. 93) afirma que "se consideramos o mundo como um conjunto de possibilidades, o evento é um veículo de uma ou algumas dessas possibilidades existentes no mundo."

O que há de fundo comum entre Stengers, Latour, Ingold, Deleuze, Guattari, Santos, entre outros pesquisadores que apontam críticas aos métodos científicos aristotélico e cartesiano? Para encontrarmos respostas, precisamos buscar não na Europa, mas nas Américas. Tais críticas remontam, por exemplo, ao Filósofo e Antropólogo francês Pierre Clastres (1934-1977), que pesquisou Povos Indígenas da América do Sul, envolvendo as etnias Guayaki, Guarani e Yanomami. Clastres publicou o livro A Sociedade Contra o Estado (1977), com a tese que sociedades com poder centralizado aos moldes europeus não eram nem mais nem menos evoluídas, comprovando com etnografias que Povos Indígenas são organizados de forma descentralizada, com suas complexidades e estratégias para impedir o surgimento do poder centralizado que origina o Estado. As pesquisas de Clastres influenciaram diretamente os filósofos Deleuze e Guattari. 
O pressentimento da chegada do Estado deixa de ser misterioso se o pensamos como uma força que age sobre as sociedades primitivas obrigando-as a exercer uma força contrária com o intuito de conjurar e impedir o seu aparecimento. Essa é a grande contribuição do pensamento etnológico de Clastres para a teoria de Deleuze e Guattari a respeito do surgimento do Estado onde se encontra a definição das sociedades primitivas a partir do processo maquínico de conjuraçãoantecipação. (FORNAZARI, 2018, p. 29)

Contudo, uma geração anterior a eles foi influenciada pelo pensamento processual da Filosofia do Processo, que inclui a mudança como fator para pensar a realidade, do filósofo inglês Alfred North Whitehead (1861-1947), que retomou o fluxo de Heráclito de Éfeso (500-450 a. C), mesclando com o pragmatismo do filósofo estadunidense William James (1842-1910) e conformando a Filosofia Especulativa.

n'A dobra (1988), Deleuze já citava os nomes de Henry e de Wiliam James e fazia de Whitehead o autor da "terceira grande lógica do acontecimento" (LP, p. 72) e verdadeiro "sucessor" de Leibniz. (SANTOS, B., 2017, p. 2)

Para James, o universo aparece como uma pluralidade indefinida de partes ligadas entre si, que constituem a nossa experiência, e nada nos informa acerca da unidade que presidiria a essa pluralidade, formando sistema coeso, finito ou infinito (LEOPOLDO, 2001, p. 195). William James afirma que "a experiência é um processo que continuamente nos dá novo material para digerir. Lidamos com isso intelectualmente pela massa de crenças que já possuímos, assimilando, rejeitando ou reorganizando em diferentes graus" (JAMES, 1978, p. 208). Com James, retomamos a presença de Povos Indígenas nas influências a críticas ao pensamento eurocentrado. James esteve no Brasil nos anos 1865 e 1866, quando viajou para o Rio de Janeiro; depois foi para a Amazônia, passando por Belém do Pará, Manaus e subiu o Rio Solimões. Naquele período, experienciou a vida em comunidades ribeirinhas e teve contato com a vida indígena amazônica. Segundo Maria Helena P. T. Machado, no texto O Adão Norte-Americano no Éden Amazônico, da obra O Brasil no olhar de William James: cartas, diários e desenhos 1865-1866, 
De fato, já nesse período o jovem James mostrava traços que, mais tarde, foram seguidamente apontados por seus biógrafos como fundamentais à sua forma de ver o mundo, quais sejam: empatia e relativismo. [...] Ainda assim, embora seus biógrafos sublinhem que o ano passado no Brasil tenha tido consequências importantes na definição profissional, suas cartas foram quase exclusivamente analisadas em termos da formação de seu pensamento e como prováveis testemunhas dos primeiros movimentos que o levaram à formulação do pragmatismo. [...] Apesar dos percalços, sua viagem ao Brasil é discutira por seus biógrafos como ponto decisivo na vida do filósofo do pragmatismo, pois teria sido ali que James decidira se dedicar à Filosofia. (MACHADO, 2010, p. 16-17)

Temos, portanto, duas gerações de pensadores influenciados diretamente por experiências, vivências e diálogos com o pensamento de Povos não Europeus, sendo William James, em 1866, e Pierre Clastres um século depois. Contudo, temos o brasileiro Milton Santos ordenando e organizando esses pensamentos diante da Geografia e Geopolítica em suas obras, salientando A Natureza do Espaço de 1996. Santos organizou seu pensamento incluindo os humanos com seus sistemas técnicos, cuja sucessão nos dá a história do Espaço Geográfico, que é "a soma indissolúvel de sistemas de objetos e sistemas de ações". E continua

Esses objetos e essas ações são reunidos numa lógica que é, ao mesmo tempo, a lógica da história passada (sua datação, sua realidade material, sua causação original) e a lógica da atualidade (seu funcionamento e sua significação presentes). Trata-se de reconhecer o valor social dos objetos, mediante um enfoque geográfico. A significação geográfica e o valor geográfico dos objetos vêm do papel que, pelo fato de estarem em contiguidade, formando uma extensão contínua, e sistemicamente interligados, eles desempenham no processo social. (SANTOS, M., 2006, p. 49)

Na linguagem da geometria, novos padrões foram elaborados na Geometria não Euclidiana (Figura 6 e Figura 7), estabelecendo curvaturas no espaço que possibiltaram ir além da unidade e dualidades, incluindo a multiplicidade no pensamento, nos cálculos e na percepção da realidade. 
Figura 6 - Geometria Diferencial, não Euclidiana

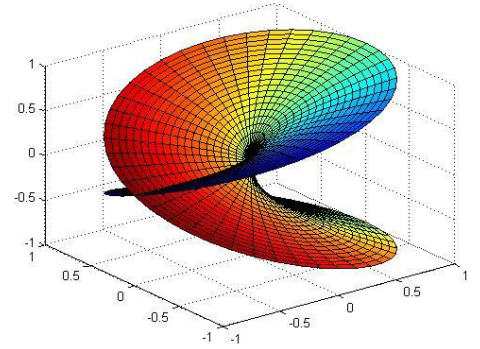

Fonte: Página do Verbete no Wikipédia ${ }^{6}$.
Figura 7 - Analogia da curvatura do espaço-tempo de Einstein

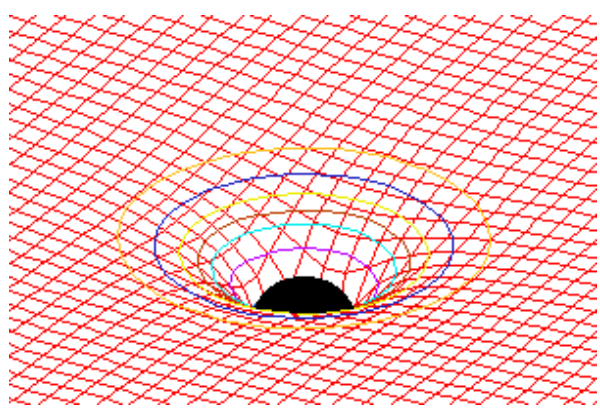

Fonte: Página do Verbete no Wikipédia?.

A Filosofia do Processo, por sua vez, tem fortes raízes em epistemologias não eurocentradas, bem como o Pragmatismo. Com isso, gostaríamos de incluir uma ferramenta conceitual para designar atividade intelectual não aristotélica e não cartesiana, fundamentadas estas no pensar/pesar da balança: sugerimos "Apensar" e "Apensamento" no sentido de anexar, ordenar, organizar, para referirmo-nos às Filosofias Indígenas.

\section{Apensamento fractal}

Apensar parece-nos um conceito que amplia a dualidade, isto é, a necessidade de pesar entre dois pesos para verificar qual deles é o único e verdadeiro. A forma Lógica da não contradição ou do terceiro excluído de Aristóteles apresenta-se como delimitador do pensamento, sendo que obrigatoriamente necessita apenas duas premissas para chegar a uma única conclusão. Contudo, o apensamento necessitaria incluir premissas ao invés de excluí-las. Sabemos que os números são ferramentas responsáveis por boa parte da expansão colonial europeia, após a matemática adentrar nos métodos de navegação e contabilidade. Porém, nem a matemática dos números naturais nem a geometria apresentavam-se conforme as experiências com a natureza, sendo que esta se apresenta

\footnotetext{
${ }^{6}$ Disponível em: <https://pt.wikipedia.org/wiki/Superficie_de_Riemann>. Acesso em: 13 abr. 2021.

7 Disponível em: <https://pt.wikipedia.org/wiki/Equacoes_de_campo_de_Einstein >. Acesso em: 13 abr. 2021.
} 
irregular e fragmentada, fora dos padrões da Geometria Euclidiana. Com isso, temos como crítica as influências do matemático polonês Benoit B. Mandelbrot (1924-2010) e o físico suíço/iraniano Nassim Haramein (1962-) que têm suas pesquisas desenvolvidas não mais a partir de padrões dos sólidos platônicos e padrões aristotélicos, mas da observação de padrões que se apresentam na natureza, conforme seus fluxos e processos empiricizados no tempo (SANTOS, M., 2006).

Mandelbrot questionava "por que a geometria é chamada de fria e seca? Uma das razões encontra-se na sua incapacidade de descrever a forma de uma nuvem, uma montanha, um litoral ou uma árvore. Nuvens não são esferas, montanhas não são cones, litorais não são círculos, e cascas de árvores não são regulares e polidas, nem relâmpagos viajam em uma linha reta" (MANDELBROT, 1983, p. 1).

Em Mil Platôs (2012), Deleuze e Guattari estavam também influenciados, além de Clastres, Whitehead e James, por Mandelbrot: "Seria possível dar uma definição matemática muito geral dos espaços lisos? Parece que os 'objetos fractais', de Benoit Mandelbrot, vão nessa direção. São conjuntos cujo número de dimensões é fracionário ou não inteiro, ou então inteiro, mas com variação contínua de direção" (DELEUZE; GUATTARI, 2012, p. 171). Conforme a historiadora Ana Carolina Pereira, em Teorizando o tempo fractal: um diálogo entre Teoria da História, Antropologia e a teoria dos fractais, é utilizada para estudos com Povos Indígenas.

Desenvolvida pelo matemático Benoit Mandelbrot, a teoria dos fractais vem sendo aplicada em diversas áreas do conhecimento e, extrapolando as fronteiras das ciências físico-matemáticas, vai das pesquisas em economia às ciências da computação, geologia, geofísica, biologia, psicologia, educação, além de outras. A discussão sobre esta teoria concentra-se, contudo, na sua apropriação pela antropologia, dada a recorrência de sua utilização nos estudos do parentesco ameríndio. (PEREIRA, 2011, p. 1).

Roy Wagner (1938-2018), antropólogo estadunidense, também influenciado pelos questionamentos à dualidade e matemática eurocentrada, buscou definir as relações sociais de Povos da Melanésia, na Oceania, como pessoa fractal afirmando que é "noção 
matemática de uma dimensionalidade que não pode ser expressa em números inteiros" (WAGNER, 2011, p. 4).

Percebemos a dificuldade dos Filósofos em definir fractal e, por isso, buscamos por Matemáticos especialistas.

A figura geométrica ou objeto natural que combinar as seguintes características pode ser chamado de fractal, de acordo com Mandelbrot (1983): as partes têm a mesma forma ou estrutura que o todo, estando, porém, em uma escala diferente e podendo estar um pouco deformadas; a sua forma é extremamente irregular, interrompida ou fragmentada, assim como todo o resto, qualquer que seja a escala de observação; contém elementos distintos cujas escalas são muito variadas. (SEDREZ, 2010, p. 46)

Figura 8 - Comparação entre geometria euclidiana e geometria fractal

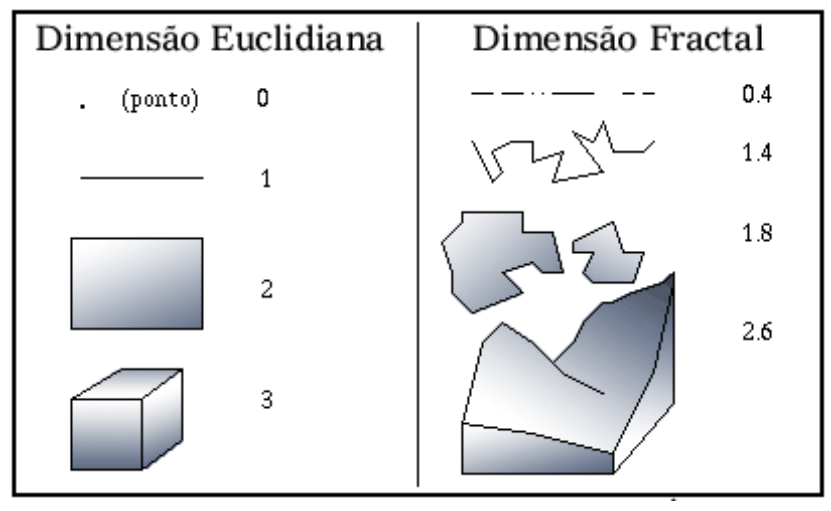

Fonte: SIQUEIRA, 2005, p. 24.

As análises de bacias de rios sob a perspectiva fractal permitiram o aprofundamento de estudos geográficos. A partir da imagem visual do fractal, podemos pensar territorialmente a dimensão fractal de redes de drenagem de bacias hidrográficas, estudada por Tarboton et al. em Fractal Nature of river network (1988). As bacias hidrográficas conformam geograficamente o padrão fractal e, analisada num mapa, servem como referência para possível identificação dos fluxos entre rios menores e maiores, em relação assimétrica. Essa relação foi classificada por R. E. Horton (1945), modificada por A. N. Strahler (1964), como uma classificação que reflete o grau de ramificação ou bifurcação dentro de uma bacia hidrográfica (GUIMARÃES, 2017, p. 12). 
Nesta classificação atribui-se um número de ordem a cada curso de água sendo classificadas como cursos de água de $1^{\text {a }}$ ordem aqueles que não apresentem afluentes. A linha de água formada pela junção de duas linhas de água com a mesma ordem tomará uma ordem maior em um. Assim, a junção de dois rios de ordem $n$ dá lugar a um rio de ordem $n+1$. Por exemplo, $1+1=2 ; 3+3=4 ; 2+2=3$, etc. A linha de água formada pela junção de duas linhas de água de ordens diferentes tomará a ordem maior das duas. Assim, a junção de um rio de ordem $\mathrm{n}$ com um rio de ordem $n+1$, dá lugar a um rio de ordem $n+1$. Por exemplo, $1+2=2 ; 1+3$ $=3 ; 2+3=3$, etc. (GUIMARÃES, 2017, p. 12)

Figura 9 - Rede de drenagem do Ribeirão Marmelo que pertence à bacia hidrográfica do rio Paraíba do Sul, estudado por metodologia fractal

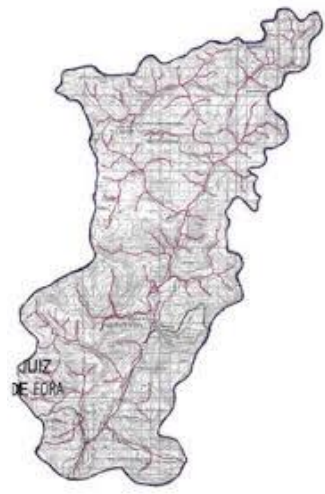

Fonte: MARQUES; BORTONI; GOMES, 2013, p. 102.

Contudo, a proposta fractal auxiliou como ferramental não apenas a Matemática, a Geometria e a Geografia. Na Antropologia, Roy Wagner buscou com ela compreender os melanésios e a constituição das figuras de liderança como integralmente implicadas e não em unidade (WAGNER, 2011). José Antonio Kelly Luciani, Antropólogo venezuelano que atua no Brasil, escreveu sobre Fractalidade e Troca de Perspectiva, e relata que

O englobamento através da troca de uma parte da pessoa leva-nos à qualidade fractal a que quero me referir: o encerramento do todo (de uma pessoa) na parte (de uma pessoa); a conversão de partes de pessoas em pessoas inteiras. Tudo isso é, basicamente, uma expressão do caráter contextual das categorias nós/outros a que nos referimos antes, e uma outra expressão da fractalidade: a pessoa-como-grupo é uma versão em escala ampliada da pessoa-como-indivíduo e uma versão 
duas vezes ampliada da pessoa como-parte. O que se tornará evidente adiante é que a personitude fractal implica que relações entre pessoas, em qualquer escala, são réplicas umas das outras, isto é, são autosimilares. (KELLY, 2001, p. 102)

Ainda, Kelly (2001, p. 127) afirma que "há, certamente, muito mais na teoria dos fractais do que a auto-similaridade escalar. O que estou tomando emprestado da matemática é a imagem de figuras que apresentam a mesma forma em diferentes escalas". Marcela Stockler Coelho de Souza (2017, p. 99), antropóloga brasileira, analisando o futuro da Antropologia relata que "tomando como motivo uma sequência de imagens - portas, árvores, fractais, rios e bacias -, [...] procura apontar e comentar alguns dos desafios e implicações para a antropologia em geral”.

Mais uma ferramenta conceitual para analisarmos é a escalaridade presente no fractal. Segundo a antropóloga brasileira Letícia Cesarino, "a problemática da escala está no cerne da constituição da disciplina antropológica enquanto tal” (CESARINO, 2014).

Como notado por Strathern e outros, essas manobras de escala (scaling) costumam envolver outros modos comuns de colocar-em-relação, tais como analogias, contextualizações (context-making) e atribuição a domínios (domaining). Nessa perspectiva, contextualizar não significa encaixar unilateralmente, e definitivamente, elementos novos (por exemplo, os "dados" levantados na pesquisa etnográfica) no contexto correto (normalmente concebido em termos de uma escala macro também "dada" de antemão na academia, como "globalização", ou "governamentalidade"), mas olhar para o modo como os próprios contextos são feitos no campo e no gabinete. Em seus escritos, Strathern tem enfatizado o modo como esse acionamento de escalas, contextos e domínios envolve o rearranjo, eclipsamento e realce seletivo de certos elementos, com base em certas matrizes relacionais bem estabelecidas. Estas últimas são frequentemente pensadas em termos de binarismos recorrentes como, no caso da antropologia, natureza versus cultura, indivíduo versus sociedade, dádiva versus mercadoria. (CESARINO, 2014, p. 26-27) 
O Geógrafo estadunidense, Andrew J. Herod, aponta que "as escalas são socialmente produzidas e a definição das escalas influencia e repercute na vida social (HEROD, 2011 apud SOLER, 2019, p. 3).

Figura 10 - Escalas
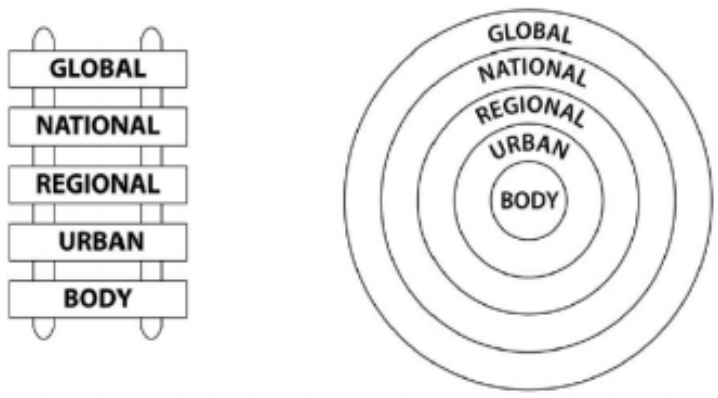

Fonte: SOLER, 2019, p. 3.

Observando, por exemplo, a Convenção 169, de 1989, da Organização Internacional do Trabalho - OIT (SILVA, 2008, p. 54), a multiescalaridade que deve ser respeitada com Povos Indígenas e Tribais é referente a culturas e valores espirituais e sua relação com as terras ou territórios, conforme o artigo 13 da referida Convenção. Em seu artigo $5^{\circ}$ está especificado que "deverão ser reconhecidos e protegidos os valores e práticas sociais, culturais, religiosos e espirituais". Poderia a diferenciação ser definida em termos de escala? Se pensarmos sob a perspectiva fractal, do maior para o menor, poderíamos supor que todos fazem parte da mesma "bacia espiritual" que contém práticas religiosas, que por sua vez contém práticas culturais efetivadas pela sociedade que a mantém como arcabouço de valores.

Do menor para o maior, usando a escala da temporalidade, poderíamos supor que os valores mantidos cotidianamente, reforçados por meio de práticas culturais rotineiras, estruturadas em forma religiosa, garantem bem-estar espiritual por longo período. Contudo, relacionando com a escalaridade territorial, teríamos que os valores mantidos pelas práticas culturais da sociedade, em sua comunidade, garantem a permanência da cultura regional, compartilhada com demais seguidores das mesmas práticas religiosas e 
garantem bem-estar espiritual para todo o território daquele povo. Desse modo, a multiescalaridade fractal poderia auxiliar em estudos com vistas a dialogar, por exemplo, com projetos para criação de políticas públicas como processos de identificação territorial a ser usufruído por determinada população.

A proposta de incluir a multiplicidade e a multiescalaridade a partir do fractal permite, como a Filosofia do Processo de Whitehead, organizar o Apensamento, ordenando as ideias, os argumentos, as percepções, os conceitos, a partir de sua localização na escala espacial e temporal, o que possibilita a elaboração de Cosmografias junto a Povos Indígenas aproximando-nos de suas Filosofias e descolonizando as análises e estudos das influências eurocentradas.

\section{Apensamentos Indígenas}

No texto Orientações básicas para a caracterização ambiental de terras indígenas em estudo, publicado pela Fundação Nacional do Índio (TEMPESTA, 2013), o conceito de “cosmografia” ajuda no entendimento da relação particular que um grupo social mantém com o território.

\footnotetext{
Cosmografia se refere, segundo Paul Little (2002), aos "saberes ambientais, ideologias e identidades coletivamente criados e historicamente situados que um grupo social utiliza para estabelecer e manter seu território. A cosmografia de um grupo inclui seu regime de propriedade, os vínculos afetivos que mantém com seu território específico, a história da sua ocupação guardada na memória coletiva, o uso social que dá ao território e as formas de defesa dele". (TEMPESTA, 2013, p. 13)
}

A cosmografia precisa ser realizada por equipe técnica e esta deve respeitar as categorias nativas da "propriedade" ao longo do território a ser estudado. Para tanto, seguindo a Convenção 169, que rege sobre o respeito aos valores espirituais quanto à terra ou ao território, um conceito utilizado como ferramenta etnológica é o de "donomestre", conforme aponta o Antropólogo brasileiro Carlos Fausto em "Donos demais: maestria e domínio na Amazônia": 
O mundo pós-mítico que surge dessa dinâmica inicial é um mundo de múltiplos domínios. Esses domínios são constitutivos da estrutura do cosmos, de tal modo que um dos pressupostos a reger a ação humana sobre o que chamaríamos de mundo natural é o de que tudo tem ou pode ter um dono. Como mostrou Descola (1986), a natureza é doméstica porque é sempre o domus de alguém. (FAUSTO, 2008, p. 339)

O mundo estaria, conforme Fausto, dividido em domínios, "em diferentes espaços de domesticidade pertencentes a humanos e a não-humanos, cada qual com os seus donos-mestres" (FAUSTO, 2008, p. 339).

Em suma, tudo em princípio tem ou pode ter um dono: a floresta, os animais, os rios e as lagoas, mas também uma espécie animal, outra espécie vegetal, ou ainda aquele bambuzal, aquela curva de rio, determinada árvore, uma montanha particular. (FAUSTO, 2008, p. 340)

Diante o exposto, para realizar uma Cosmografia conforme Little, é necessário respeitar a Convenção 169 e dialogar com a comunidade interessada para incluí-los com radicalidade nas metodologias de mapeamentos temáticos e buscando registrar cartograficamente o cosmos na percepção da tradição indígena estudada, observados os avanços da Cartografia Social fundamentada na investigação-ação-participativa (ACSELRAD, 2008).

Vejamos (Tabela 1) a diversidade de conceitos ameríndios do Brasil como denominação de donos-mestres, coletados por Fausto (2008).

Tabela 1 - Alguns conceitos sobre donos-mestres na Antropologia compilados pelo autor

\begin{tabular}{|c|c|c|c|}
\hline Autor & $\begin{array}{c}\text { Povo } \\
\text { (Tronco) }\end{array}$ & Conceito & Descrição \\
\hline $\begin{array}{l}\text { SEEGER, Anthony. } 1981 . \\
\text { Nature and society in } \\
\text { Central Brazil: the Suyá } \\
\text { indians of Mato Grosso. } \\
\text { Cambridge, MS: Harvard } \\
\text { University Press. }\end{array}$ & Suyá (Gê) & Kande & $\begin{array}{l}\text { “A maioria das coisas tem donos- } \\
\text { controladores: aldeias, cerimônias, cantos, } \\
\text { casas, roças, bens, animais de estimação e } \\
\text { assim por diante. A importância de kande é } \\
\text { bem difusa" (1981:182). O termo kande } \\
\text { (“dono-controlador”) aplica-se não apenas à } \\
\text { posse de bens tangíveis e intangíveis (como o }\end{array}$ \\
\hline
\end{tabular}




\begin{tabular}{|c|c|c|c|}
\hline & & & $\begin{array}{l}\text { conhecimento ritual), mas também à } \\
\text { habilidade potencial para produzi-los. Ele } \\
\text { forma ainda expressões para designar funções } \\
\text { de prestígio e poder político: assim, os líderes } \\
\text { beligerantes eram denominados } \\
\text { weropakande, "donos de nossa aldeia”, } \\
\text { enquanto o especialista ritual é conhecido } \\
\text { como mërokïnkande. Seeger afirma que kande } \\
\text { é "o conceito mais importante no } \\
\text { pensamento suyá sobre poder" (1981:181)." (p. } \\
\text { 330). }\end{array}$ \\
\hline $\begin{array}{l}\text { VIVEIROS DE CASTRO, } \\
\text { Eduardo. 2002a. “Esboço } \\
\text { de cosmologia yawalapíti”. } \\
\text { In: A inconstância da alma } \\
\text { selvagem. São Paulo: } \\
\text { Cosac \& Naify. pp. } 25-85 .\end{array}$ & Yawalapiti & Wököti & $\begin{array}{l}\text { "Designa o patrono ritual, o mestre } \\
\text { especialista de cantos, o senhor de espécies } \\
\text { animais ou vegetais, o chefe representante, } \\
\text { ou o proprietário em sentido ordinário. Em } \\
\text { todas essas denotações, está se definindo a } \\
\text { relação de um sujeito com um recurso: o dono } \\
\text { seria o mediador entre esse recurso e o } \\
\text { coletivo ao qual pertence." (p. } 330) \text {. }\end{array}$ \\
\hline FAUSTO, 2008 & $\begin{array}{l}\text { Kuikuro } \\
\text { (Karib) }\end{array}$ & Oto & $\begin{array}{l}\text { "Envolve controle e proteção, é marcada pela } \\
\text { oferta alimentar: os pais são "nossos donos" } \\
\text { (kukoto), pois cuidam de nós e nos alimentam. } \\
\text { De mesmo modo, ser dono de estruturas } \\
\text { coletivas - há donos do caminho (ama oto), } \\
\text { da casa dos homens (kuakutu oto), da praça } \\
\text { central (hugogó oto), da aldeia (eté oto) - } \\
\text { implica cuidado, pois cabe ao dono manter } \\
\text { essas estruturas e alimentar as pessoas que } \\
\text { trabalham para esse fim." (p. } 331 \text { ). }\end{array}$ \\
\hline $\begin{array}{l}\text { BRIGHTMAN, Marc. } 2007 . \\
\text { Amerindian leadership in } \\
\text { Guianese Amazonia. } \\
\text { Doctoral thesis, } \\
\text { Department of Social } \\
\text { Anthropology, University } \\
\text { of Cambridge. }\end{array}$ & $\begin{array}{l}\text { Trio } \\
\text { (Karib) }\end{array}$ & Entu & $\begin{array}{l}\text { "Possui o sentido tanto de ‘dono' como de } \\
\text { ‘patrão"” (2007:83). Ele não se aplica a } \\
\text { qualquer relação de posse, mas sim ao que o } \\
\text { autor denomina temporary controlled } \\
\text { possession. O fundador e líder de uma aldeia é } \\
\text { seu pata entu, assim como aquele que } \\
\text { controla o funcionamento do rádio } \\
\text { comunicador é radio entu. Entu significa ainda } \\
\text { “tronco de árvore” e “piemonte”, cujos traços } \\
\text { semânticos "estar na origem de" e "ser a base } \\
\text { de” aparecem também em outros contextos } \\
\text { etnográficos." (p. } 331 \text { ) }\end{array}$ \\
\hline $\begin{array}{l}\text { VIVEIROS DE CASTRO, } \\
\text { Eduardo. 1992. From the } \\
\text { enemy's point of view: } \\
\text { humanity and divinity in an } \\
\text { amazonian society. } \\
\text { Chicago: University of } \\
\text { Chicago Press }\end{array}$ & $\begin{array}{l}\begin{array}{l}\text { Tupi- } \\
\text { guarani }\end{array} \\
\text { Araweté } \\
\text { Parakanã }\end{array}$ & $\begin{array}{l}\text {-jar } \\
\text { ñã } \\
\text {-jara }\end{array}$ & $\begin{array}{l}\text { “Liderança, controle, representação e } \\
\text { propriedade de certo recurso ou domínio” (p. } \\
\text { 331) }\end{array}$ \\
\hline DÉLÉAGE, Pierre. 2005. Le & Sharanahu & Ifo & "Designa o genitor em relação a seus filhos, o \\
\hline
\end{tabular}




\begin{tabular}{|c|c|c|c|}
\hline $\begin{array}{l}\text { chama- nisme sharanahua: } \\
\text { enquête sur } \\
\text { l'apprentissage et } \\
\text { l'épistémologie d'un rituel. } \\
\text { Thèse de doctorat, Paris, } \\
\text { EHESS. }\end{array}$ & a (Pano) & & $\begin{array}{l}\text { chefe em relação ao seu pessoal, o } \\
\text { proprietário em relação aos objetos de sua } \\
\text { posse, o dono em relação aos animais } \\
\text { domésticos." } \\
\text { "O dono está na origem daquilo que possui, } \\
\text { pois o fabricou, seja este artefato pessoa ou } \\
\text { coisa: na Amazônia, a noção de fabricação não } \\
\text { se aplica apenas aos objetos, mas também aos } \\
\text { corpos de parentes e de animais familiares. Ifo } \\
\text { designa ainda um tipo de entidade: os mestres } \\
\text { de animais e vegetais com os quais os xamãs } \\
\text { interagem" (p. } 332 \text { ). }\end{array}$ \\
\hline $\begin{array}{l}\text { HULTKRANTZ, Ake. } 1961 . \\
\text { "The owner of the animals } \\
\text { in the religion of north } \\
\text { american Indians". In: A. } \\
\text { Hultcrantz (org.), The } \\
\text { supernatural owners of } \\
\text { nature. Stockholm: } \\
\text { Almqvist and Wiksell. pp. } \\
53-64 \text {. }\end{array}$ & -- & -- & $\begin{array}{l}\text { "A literatura restringiu-se a essas figuras ao fa- } \\
\text { lar de donos ou mestres, apresentando-as } \\
\text { como hipérboles da espécie que representam } \\
\text { ou a forma antropomórfica pela qual se } \\
\text { apresentam aos xamãs." }\end{array}$ \\
\hline $\begin{array}{l}\text { CESARINO, Pedro N. } 2008 . \\
\text { Oniska - A poética do } \\
\text { mundo e da morte entre os } \\
\text { Marubo da Amazônia } \\
\text { ocidental. Tese de } \\
\text { doutorado, PPGAS-Museu } \\
\text { Nacional, Universidade } \\
\text { Federal do Rio de Janeiro. }\end{array}$ & $\begin{array}{l}\text { Marubo } \\
\text { (Pano) }\end{array}$ & Ivo & $\begin{array}{l}\text { "Os donos dos animais "replicam a mesma } \\
\text { configuração que caracteriza os donos de } \\
\text { maloca (shovõ ivo) marubo: ambos são chefes } \\
\text { de suas casas, nas quais habitam com suas } \\
\text { famílias e seus costumes [...]" (2008:25). Os } \\
\text { mestres dos animais, portanto, são donos em } \\
\text { seu próprio meio, contendo em si um coletivo: } \\
\text { eles representam e contêm uma espécie." (p. } \\
332 \text { ) }\end{array}$ \\
\hline $\begin{array}{l}\text { COSTA, Luiz Antonio. } 2008 . \\
\text { "Our body is our owner } \\
\text { and our chief". Séminaire } \\
\text { des Américanistes. EHESS, } \\
\text { Paris. Ms. }\end{array}$ & $\begin{array}{l}\text { Kanamari } \\
\text { (Katukina) }\end{array}$ & -warah & $\begin{array}{l}\text { "Designa o dono, o chefe, o corpo, o tronco, o } \\
\text { rio principal." } \\
\text { "O termo é sempre afixado a um sujeito, de tal } \\
\text { maneira que “uma pessoa sempre será } \\
\text { 'chefe/corpo/dono' em relação a alguma coisa, } \\
\text { a alguém ou a algumas pessoas". }\end{array}$ \\
\hline
\end{tabular}

Fonte: FAUSTO, 2008.

Para Fausto, a relação entre os donos-mestres e sua "posse" é a assimetria, em que "os donos controlam e protegem suas criaturas, sendo responsáveis por seu bemestar, reprodução, mobilidade". Fausto (2008, p. 334) define que tal relação não implica controle, mas no cuidado que o dono-mestre tem com suas crias. A assimetria, segundo o autor, "é muitas vezes concebida como uma forma de englobamento e pode se expressar como uma relação conteúdo-continente".

Como ferramenta visual dessa assimetria entre dono-mestre e suas criaturas, bem 
como, seus criadores, alguns antropólogos propõem a forma "fractal" como ferramenta, sendo esta definida por Benoit B. Mandelbrot (1982) como objetos que reproduzem as mesmas propriedades em diferentes escalas.

O caráter múltiplo e fractal das relações de domínio requer pessoas internamente compósitas, "diferentes de si mesmas" (Viveiros de Castro 2002b:377). O modelo do agente não é, assim, o do proprietário que anexa coisas a um Si imutável, mas o do mestre que contém múltiplas singularidades. (FAUSTO, 2008, p. 341)

Obtém-se, desse modo, um padrão fractal que pode ser visualmente utilizado em cosmografia de territórios indígenas referenciando-se aos donos-mestres na cosmologia tradicional, devido a sua disposição multiescalar (Figura 12) sendo: 4 dono-mestre de 3, 2 e 1; 3 dono-mestre de 2 e 1; 2 dono-mestre de 1.

Figura 11 - Classificação dos cursos de água segundo Horton-Strahler

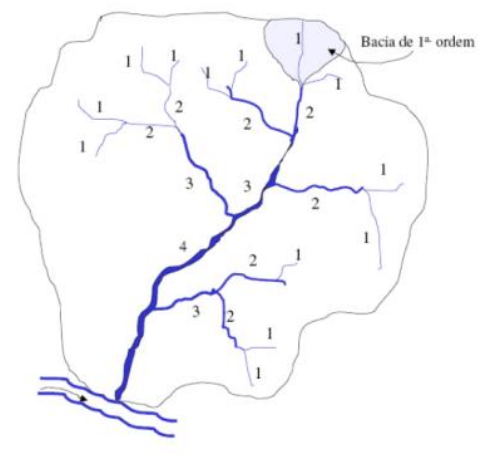

Fonte: (GUIMARÃES, 2017, p. 13).

Fausto afirma que "a topologia é sempre complexa, pois os auxiliares dos xamãs aparecem, ao mesmo tempo, como partes internas e externas do dono-mestre" (2008, p. 334). Neste ponto, Fausto comenta em nota de rodapé, aprofundando a relação topológica dos donos, e afirmando que "analisando as visões da ayahuasca e a relação feto-placenta entre os Piro, Gow (1999, p.237) sugere que essa topologia é a de uma garrafa de Klein, na qual o interior é simultaneamente o exterior do recipiente" (FAUSTO, 2008, p. 354). Felix Klein (1849-1925) foi um matemático alemão que estudou geometrias 
não Euclidianas. Claude Lévi-Strauss, no livro A oleira ciumenta (1986), dedicou um capítulo, chamado Mitos em garrafa de Klein, para analisar que "os mitos poderiam dar uma expressão concreta a um esquema que reflete necessidades mentais, suficientemente abstrato para ter sido concebido em qualquer lugar sem nada dever à experiência ou à observação" (LÉVI-STRAUSS, 1986, p. 197). "Qual poderia ser esse esquema?", segue questionando o antropólogo.

São mitos que, para utilizar uma forma resumida, podemos chamar de "em garrafa de Klein". O que quer dizer isso? Antes de mais nada uma observação. Esses mitos utilizam de modo marcante uma imagem, conhecida alhures, certamente, mas não tão utilizada quanto aqui: a do tubo ou cano. (LÉVI-STRAUSS, 1986, p. 198)

Figura 12 - Figura da garrafa de Klein

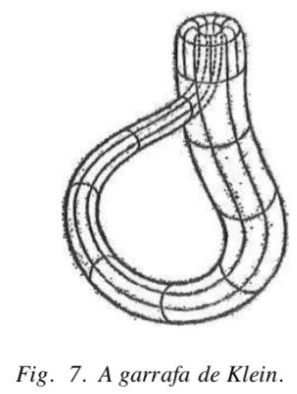

Fonte: “A oleira ciumenta”, de LÉVI-STRAUSS (1986, p. 199).

“Como compreender a recorrência de um mesmo esquema em culturas que nada têm de comparável?", pergunta Lévi-Strauss (1986). O físico Nassim Haramein nos auxilia com avanços nas pesquisas com base em dimensão fractal, para além da dimensão euclidiana, com uma proposta que supera a garrafa de Klein. O físico relatou que teve suas primeiras conclusões observando as cidades Indígenas Mayas, no México e Guatemala, e depois pesquisando outros Povos não europeus (HARAMEIN, 2003). Sua tese propôs a Teoria Unificada dos Campos, em que analisou as escalas micro e macro cósmicas, unindo a Física Subatômica com a Astrofísica. Segundo Haramein, o Universo, 
tanto micro quanto macro, se comporta como a água numa bacia que é levada a sair por um ralo, onde inicia torção criando um modelo similar ao furacão ${ }^{8}$.

O que temos no meio (do furacão)? A quietude, o olho do furacão. Você precisa de imobilidade para sermos capazes de termos um ponto de referência para a rotação. [...] E é assim que a singularidade acontece. A singularidade é o ponto central da sua experiência do Universo (HARAMEIN, 2003 apud, CAVALCANTI, 2010, p. 10).

Figura 13 - Torção da água

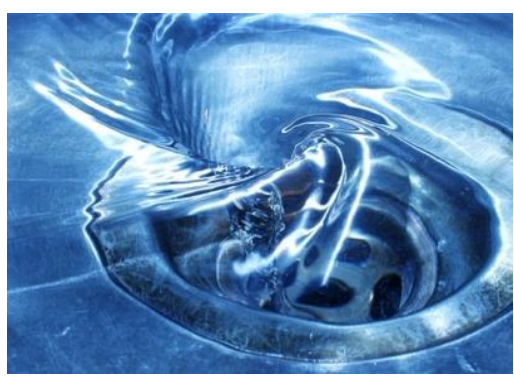

Fonte: Imagem google.
Figura 14 - Modelo esquemático da membrana topológica toroidal

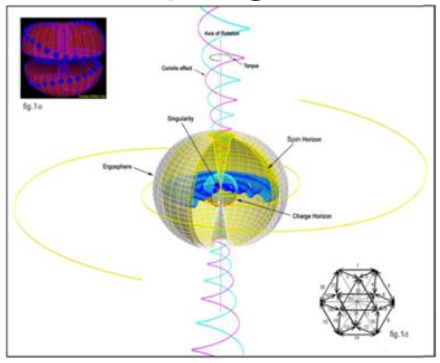

Fonte: HARAMEIN, 2008.

Ainda, Haramein afirma que o universo reproduz o padrão de torção que se expande e contrai sem cessar, que é encontrado em buracos negros, galáxias, sistemas solares, árvores e frutos no macro; e no micro, em células, átomos e partículas subatômicas. Essa topologia, afirma o físico, aparenta um duplo toro.

O toro, ou padrão primário, é uma energia dinâmica que se parece com um donut - é uma superfície contínua com um orifício. A energia flui por uma extremidade, circula em torno do centro e sai pelo outro lado. Você pode vê-lo em todos os lugares - em átomos, células, sementes, flores, árvores, animais, humanos, furacões, planetas, sóis, galáxias e até mesmo no cosmos como um todo. (HARAMEIN, 2016)

\footnotetext{
${ }^{8}$ A Etimologia de Furacão remonta a uma das entidades do Povo Indígena Taíno, da América Central e Caribe, de língua Aruake. Huracan é o deus das tormentas e ventos concêntricos, muitas vezes descritos com uma só perna e girando de braços abertos (Em http://etimologias.dechile.net/?huraca.n. Visitado em março de 2021).
} 
Figura 15- Torus

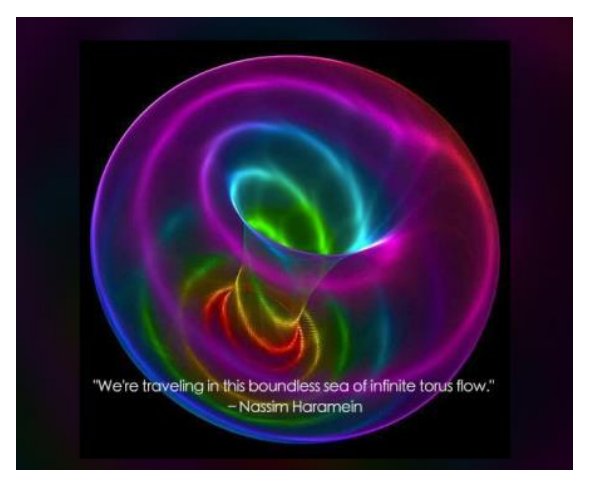

Fonte: HARAMEIN, 2016.
Figura 16 - "Em todas as escalas da natureza e do cosmos, podemos encontrar a assinatura energética de um processo de fluxo dinâmico na forma do que é chamado de torus"

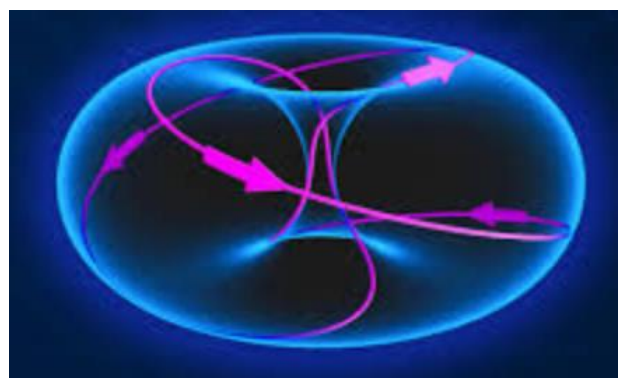

Fonte: LEFFERTS, 2019.
Figura 17 - Torus

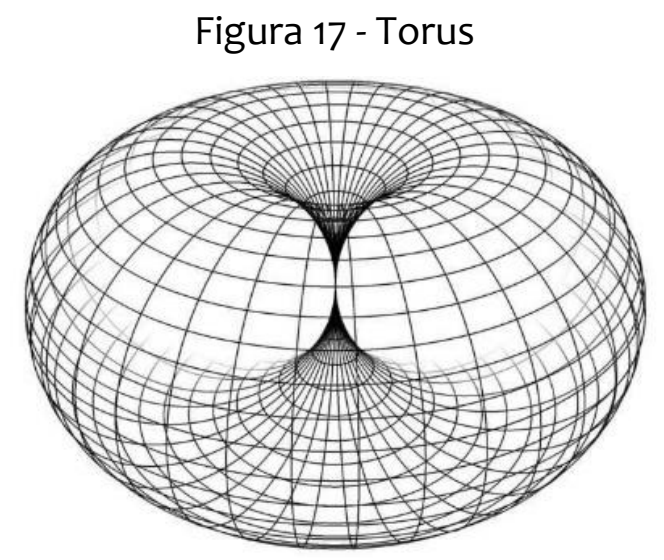

Fonte: Nassim Haramein?.
Figura 18 - Torus representado no macro e micro

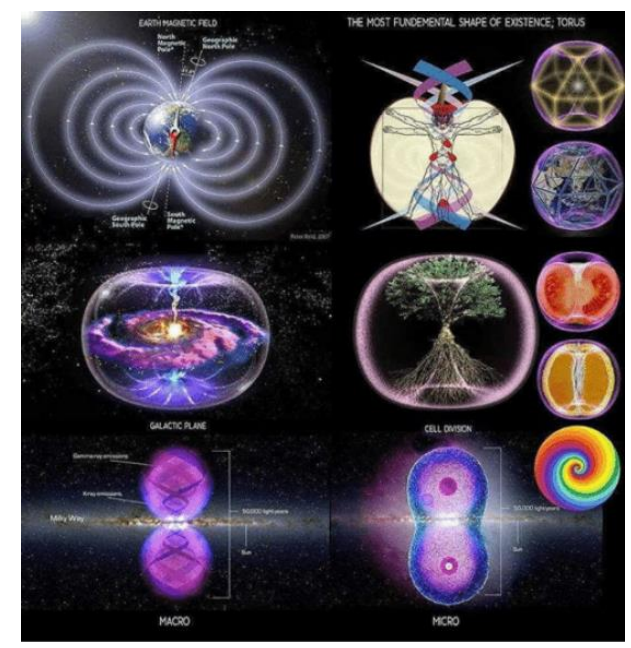

Fonte: Resonance Science Foundation ${ }^{10}$.

\footnotetext{
${ }^{9}$ Disponível em: https://thelipstickhippie.files.wordpress.com/2017/01/torus.jpg?w=1140\&h=710. Acesso em: 13 abr. 2021.

${ }^{10}$ Disponível em:

https://m.facebook.com/TheResonanceProject/photos/a.224460250920411/946009972098765/?type=3. Acesso em: 13 abr. 2021.
} 
Figura 19 - Torus superpostos

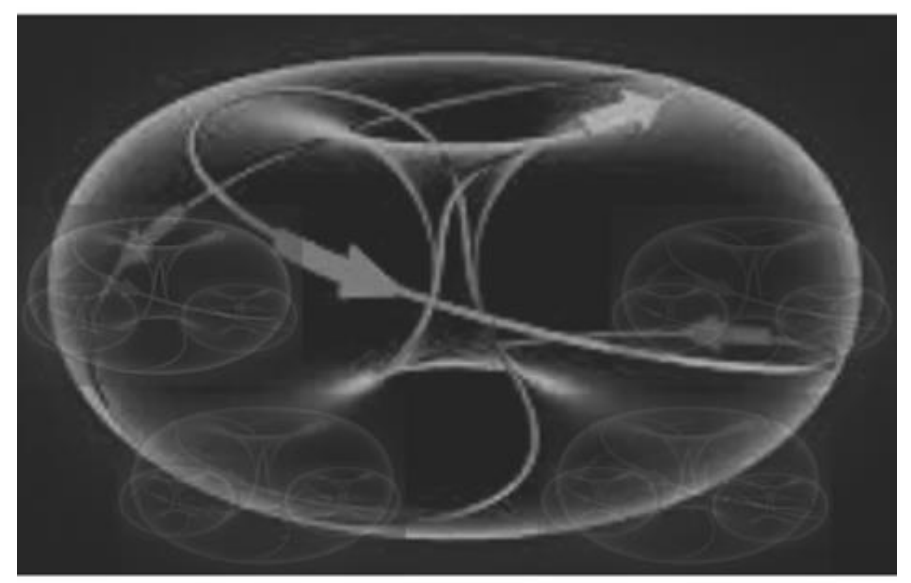

Fonte: Montagem elaborada pelo autor.

O Toro ${ }^{11}$, ou Torus, que preferimos chamar aqui de Ontoforma Torus - para diferenciar de discussões acerca da Ontologia -, como forma ôntica (existente e perceptível), é a base da teoria de Haramein que calcula as massas por meio da abordagem holográfica usando as flutuações eletromagnéticas como a estrutura do átomo. Isso permitiu focar no cálculo da massa invisível, o vácuo, dispersa ao redor do centro do Torus, percebendo o padrão nas diferentes escalas. O Torus auxilia no Apensamento, pois permite aproximar a Geometria do que vemos no mundo natural, pela fractalidade e suas escalas, bem como a Totalização do todo e das partes (SANTOS, M., 1996), como também permite a utilização das metáforas Garrafa de Klein, rizoma, rede ou malha. Contudo, seria possível o uso da ferramenta de Torus na cosmografia de donos-mestres conforme estudado na Etnologia Indígena (FAUSTO, 2008)?

\section{Torus-mestres fractais}

Como vimos na Tabela 1 sobre os Donos-mestres relacionados por Fausto (2008), a imagem do Torus nos parece aplicável a alguns seres descritos por Povos Indígenas como

\footnotetext{
${ }^{11}$ Toró é usado no Brasil para definir pé d'água, tromba d'água, tempestade, chuva forte.
} 
mediadores, protetores, comunicadores, não humanos que se apresentam aos humanos como cuidadores, que podemos chamar de Torus-mestres. Uma entidade Indígena assimilada na cultura brasileira com as características do Torus é o Saci-pererê (DA ROSA, 2014), que aparece e some por meio de redemoinhos de vento, pequenos furacões, e é considerado um dono-mestre pelo Povo Indígena Kaiowá (SOUZA, L., 2013), o segundo mais populosos do Brasil com mais de 43 mil pessoas (IBGE, 2010).

O Povo Indígena Guarani relata que na criação do mundo por Nhanderu (Nosso Pai), ele gerou Pindovy (Palmeira Eterna) para sustentar sua criação. O Jerivá é uma planta central no mundo Guarani, chamado de Pindó, que é plantado nas Aldeias em frente às Casas de Reza como protetor espiritual e percebemos que possui a forma de um Torus (Figura 20). Galante (2011) nos relata que, para os Guarani, “as palmeiras também podem representar a nervura do nosso corpo, nos dando um exemplo que parece próximo ao conceito de analogismo" (GALANTE, 2011, p. 103). Tupã, dono do trovão (Figura 22) e Yvyty, dono dos ventos (Figura 23) (GALANTE, 2011, p. 103), também podem ser considerados análogos à forma de um Torus, que podemos chamar de Ontoforma Torus ou, no caso Guarani, usar como ferramenta conceitual a "Ontoforma Pindovy”, que varia em suas dimensões escalares, do micro ao macro, conforme as narrativas tradicionais de criação do mundo (CADOGAN, 1959, p. 29, 188, 205).

Figura 20 - montagem do Jerivá com Torus

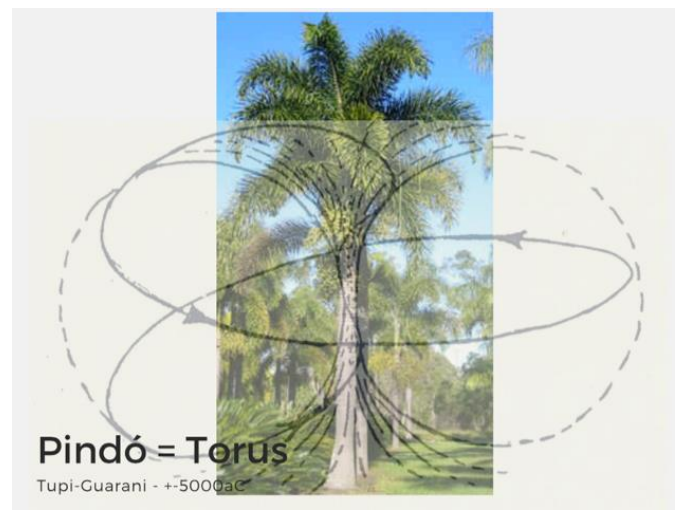

Fonte: Montagem elaborada pelo autor.
Figura 21 - Torus no corpo humano

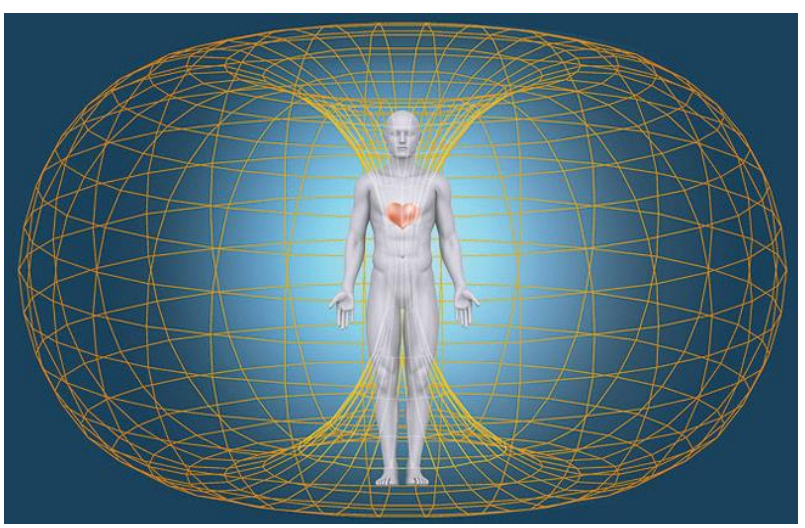

Fonte: HeartMath Institute ${ }^{12}$.

12 Disponível em: https://www.heartmath.org/research/science-of-the-heart/energetic-communication/. Acesso em: 13 abr. 2021. 
Figura 22 - Tupã (trovão) com Torus

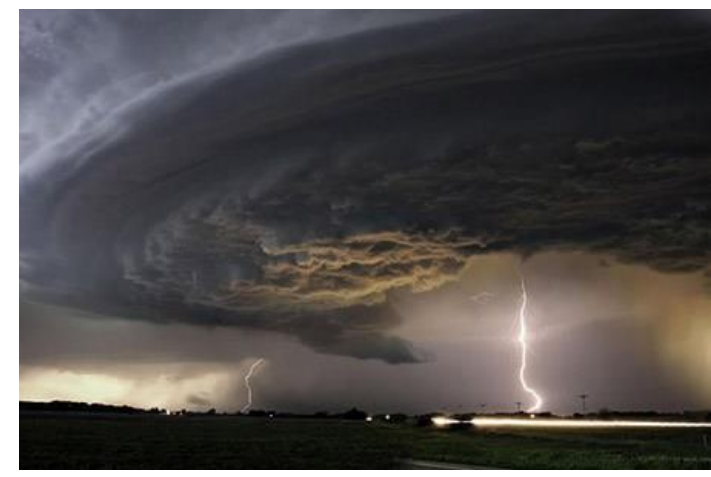

Fonte: The Torus Project, $2019^{13}$.
Figura 23 - Yvyty (ventos) com Torus

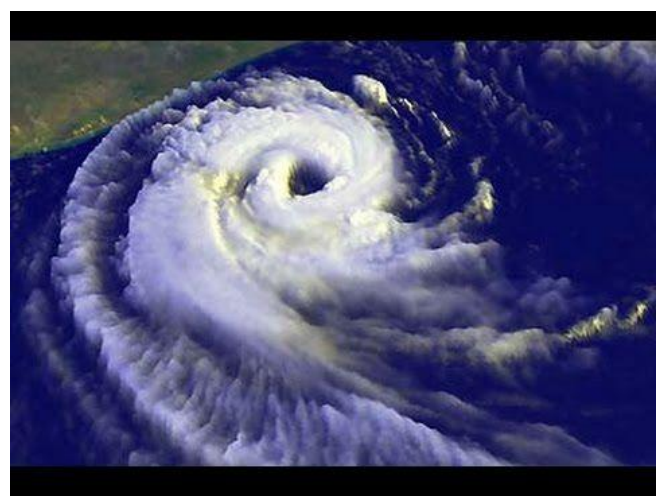

Fonte: Pinterest ${ }^{14}$.

Apensar, conforme a proposta Indígena aqui analisada, necessita descolonização da lógica aristotélica do Terceiro Excluído, pois o Apensamento exige a inclusão. Contudo, tal inclusão pode ir além da Geometria Euclidiana e Cartesiana, observando o espaço mais amplo do que duas dimensões ( $x$ e y), cabendo dentro e fora dos objetos ou seres dimensionados, outros objetos e seres, fractalmente. Essa lógica presenciada em diferentes Povos Indígenas e caracterizada pelo antropólogo francês Philippe Descola (2015) como Animismo, definido com antropogênico por considerar atribuições humanas a seres não humanos (DESCOLA, 2015, p. 26). Se utilizarmos a Ontoforma Torus ao invés da Ontoforma Humana como gênese, poderíamos substituir a percepção de "Donosmestres" por "Torus-mestres", observando suas partes visíveis e invisíveis, incluindo-as seguindo suas características de multiescalaridade e fractalidade, evitando a exclusão de terceiros e contraditórios, mas permitindo observar a multiplicidade e "o movimento conjunto do todo e das partes, através do processo de totalização" (SANTOS, M., 2006, p. 77). Com isso, teríamos uma ferramenta lógica para o Apesamento, que permitiria alcançar a complexidade das Filosofias Indígenas e decolonizar o pensar eurocentrado.

13 Disponível em: https://blog.flykit.app/the-torus-project-understanding-tornadoes-with-drones/. Acesso em: 13 abr. 2021.

${ }^{14}$ Disponível em: https://www.pinterest.pt/pin/793266921855835441/. Acesso em: 13 abr. 2021. 


\section{Considerações finais}

Diante o exposto, vimos que as Filosofias Indígenas influenciaram e influenciam fortemente as críticas ao pensamento eurocentrado, que possui base dualista da balança e dois pesos, na lógica aristotélica e na Geometria Euclidiana e Cartesiana. Contudo, as influências de Filosofias Indígenas presentes em William James e no Pragmatismo, influenciou Whitehead e a Filosofia do Processo que, por sua vez, influenciou Guattari e Deleuze que, por sua vez, foram também influenciados por Pierre Clastres que etnografou sociedades Indígenas e suas resistências contra o surgimento do Estado centralizador tão caro à Europa. Ainda, vimos as influências desses pensadores em Isabelle Stengers, Bruno Latour, Tim Ingold que trazem novas perspectivas à Antropologia e à Sociologia aberta a outras Filosofias não eurocentradas. E o arremate decolonial da Totalização de Milton Santos, o que nos auxilia a delinear a proposta de Apensar como organizar a multiplicidade (sem exclusão), composta por seres com diversidade multiescalar e fractal, tendo em comum a Ontoforma Torus que, na lógica das Filosofias Indígenas, poderíamos utilizar como ferramenta o conceito de Torus-mestres para observá-los a partir de suas particularidades perante o todo e seus movimentos, de onde se define o Apensamento como decolonização do pensar eurocentrado.

\section{Referências}

ACSELRAD, Henri; COLI, Luis Régis. Disputas cartográficas e disputas territoriais. In: ACSELRAD, Henri. et al. (org.). Cartografias sociais e território. Rio de Janeiro: Universidade Federal do Rio de Janeiro: Instituto de Pesquisa e Planejamento urbano e Regional, 2008. p. 13-43.

\section{ARISTÓTELES. Órganon, categorias, da interpretação, analíticos anteriores, analíticos} posteriores, tópicos, refutações sofísticas. São Paulo: EDI-PRO, 2005.

\section{ARISTÓTELES; PESSANHA, Jose Americo Motta. Topicos dos argumentos sofísticos:} Aristoteles: seleção de textos de Jose Americo Motta Pessanha. São Paulo: Nova Cultural, 1987. 
CADOGAN, León. Ayvu Rapyta. Textos Míticos de los Mbya-Guarani del Guairá. Universidade de São Paulo, Faculdade de Filosofia, Ciências e Letras. Boletim, n. 227, São Paulo, 1959.

CAVALCANTI, Rodrigo de Camargo. Perspectiva tridimensional no realismo jurídico. 195 f. Dissertação (Mestrado em Direito) - Pontifícia Universidade Católica de São Paulo, São Paulo, 2010. Disponível em:

https://tede.pucsp.br/bitstream/handle/5377/1/Rodrigo\%20de\%20Camargo\%20Cavalcanti.p df. Acesso em: 13 abr. 2021.

CESARINO, Letícia. Antropologia multissituada e a questão da escala: reflexões com base no estudo da cooperação sul-sul brasileira. Horiz. antropol., Porto Alegre, v. 20, n. 41, p. 19-50, jun. 2014.

DA ROSA, Rogério Reus Gonçalves. A relação afro-ameríndia entre o Negrinho do Pastoreio e o Saci-Pererê na mitologia. ANTARES: Letras e Humanidades, Caxias do Sul, v. 5, n. 10, p. 175-203, 2014.

DELEUZE, Gilles.; GUATTARI, Felix. A thousand plateaus. London: Continuum, 2004.

DELEUZE, Gilles.; GUATTARI, Felix. Mil platôs: capitalismo e esquizofrenia, vol. 5. São Paulo: Editora 34, 2012.

DESCARTES, René. Discurso do Método. São Paulo: Abril Cultural, 1973.

DESCOLA, Philippe. Além de natureza e cultura. Tessituras: Revista de Antropologia e Arqueologia, Pelotas, v. 3, n. 1, p. 7, 2015.

DIAMOND, Jared. Armas, germes e aço: os destinos das sociedades humanas. Rio de Janeiro: Editora Record, 1997.

ELIAS, Alexsânder Nakaóka. Mapa Visual: A (Des) Montagem como experimentação antropológica. ILUMINURAS, Porto Alegre: v. 21, n. 53, 2020.

FAUSTO, Carlos. Donos demais: maestria e domínio na Amazônia. Mana, Rio de Janeiro, v. 14, n. 2, p. 329-366, 2008.

FORNAZARI, Sandro Kobol. O processo maquínico primitivo: Pierre Clastres em" Mil platôs". Cadernos de Ética e Filosofia Política, São Paulo, v. 2, n. 33, p. 21-30, 2018. 
GALANTE, Luciana. Investigação etnobotânica na comunidade Guarani Mbya de Tekoa Pyau. 2011. Dissertação (Mestrado em Ciências Sociais) - Pontífica Universidade Católica SP, São Paulo, 2011. Disponível em: https://tede2.pucsp.br/bitstream/handle/3352/1/Luciana\%20Galante.pdf. Acesso em: 01 set. 2019.

GOW, Peter. Piro designs: painting as meaningful action in an amazonian lived world. Journal of the Royal Anthropological Institute, v 5, n 2, p. 229-246, Londres, 1999.

GUIMARÃES, Rita Cabral. Capítulo 2: bacia hidrográfica. In: Guimarães, Rita Cabral; Shahidian, S.; Rodrigues, C. M. (eds.). Hidrologia agrícola. 2. ed. Évora: ECT: ICAAM, 2017. p. 5-22. . Disponível em:

https://dspace.uevora.pt/rdpc/bitstream/10174/7988/1/Capitulo_2_Bacia_Hidrogr\%C3\%A1fic a.pdf. Acesso em: 13 abr. 2021.

HARAMEIN, Nassim. Conferência proferida em Rogue Valley Metaphysical Library. [S. I.: s. n.], 2003. 1 vídeo (133 min). Disponível em: https://www.youtube.com/watch?v=q1kLaIEtQ2E\&list=PLAW2zCWEQgO4_ngfI8XTfAVDG Fd2FisLL\&ab_channel=JoaquinAlvarez. Acesso em: 7 out. 2020.

HARAMEIN, Nassim.; RAUSCHER, Elizabeth. A. The orgin of spin: a consideration of torque and coriolis forces in Einstein's field equations and grand unification theory. Beyond the standard model: searching for unity in physics, Oakland, v.1, p. 153-168, 2005. Disponível em: https://resonance.is/origin-spin-consideration-torque-coriolis-forceseinsteins-field-equations-grand-unification-theory/. Acesso em: 01 set. 2019.

HARAMEIN, Nassim; HYSON, Michael; RAUSCHER, E. A. Scale unification: a universal scaling law for organized matter. In: PROCEEDINGS OF THE UNIFIED THEORIES CONFERENCE. Sec, Budapest: [s.n.], 2008. p. 11-16.

HARAMEIN, Nassim. [Photo]. 3 dez. 2016. Facebook: Nassim.Haramein.official. Disponível em: https://www.facebook.com/Nassim.Haramein.official/photos/the-torus-or-primarypattern-is-an-energy-dynamic-that-looks-like-a-doughnut-its/572141459643783/. Acesso em: 13 abr. 2021.

HEROD, Andrew. Scale. Editora Routdlege, Nova York, 2011.

IBGE. Censo de 2010. Brasília. Disponível em: https://indigenas.ibge.gov.br/. Acesso em 13 abr. 2021.

INGOLD, Tim. Trazendo as coisas de volta à vida: emaranhados criativos num mundo de materiais. Horizontes Antropológicos, Porto Alegre, v.18 n.37, p. 25-44, jan./jun. 2012. 
JAMES, William. Pragmatism and the meaning of truth. Cambridge (MA): Harvard Univesity Press, 1978.

LATOUR, Bruno.; WOOLGAR, Steve. A Vida de laboratório: a produção dos fatos científicos. Rio de Janeiro: Relume Dumará, 1997.

LEFFERTS, Marshall. Cosmometry: exploring the holo fractal nature of the cosmos. Santa Cruz, CA: Cosmometria Publishing, 2019.

LEOPOLDO, Franklin et al. Pragmatismo e humanismo: Bergson, leitor de William James. Cognitio: Revista de Filosofia, São Paulo, n. 2, p. 193-202, 2001.

LÉVI-STRAUSS, Claude. A oleira ciumenta. São Paulo: Brasiliense, 1986.

KELLY, José Antonio Luciani. Fractalidade e troca de perspectivas. Mana - Estudos de Antropologia Social. Rio de Janeiro, v. 7, n. 2, p.95-132, 2001.

MACHADO, Maria Helena, P. T. O Adão norte-americano no Éden amazônico. In: O BRASIL NO OLHAR DE WILLIAM JAMES: cartas, diários e desenhos 1865-1866. São Paulo: EdUSP, 2010. p. 14-84.

MANDELBROT, Benoit B. The fractal geometry of nature. New York: W. H. Freeman, 1982. Disponível em:

https://users.math.yale.edu/ bbm3/web_pdfs/encyclopediaBritannica.pdf. Acesso em: 13 de abr. 2021.

MARQUES, Luísa Santana; BORTONI, Samanta Ferreira; GOMES, Maria Helena Rodrigues. Determinação da dimensão fractal de redes de drenagem de Bacias Hidrográficas: um estudo de caso. Revista Eletrônica Principia: Caminhos Da Iniciação Científica, v 17, 99106, Juiz de Fora, 2013. Disponível em:

https://periodicos.ufjf.br/index.php/principia/article/view/25455. Acesso em: 4 jun. 2020.

PEREIRA, Ana Carolina B. Teorizando o tempo fractal: um diálogo entre Teoria da História, Antropologia e a teoria dos fractais. In: SIMPÓSIO NACIONAL DE HISTÓRIA, 24., 2011, São Paulo. Anais [...]. São Paulo: ANPUH, 2011. Disponível em:

http://www.snh2011.anpuh.org/resources/anais/14/1300862505_ARQUIVO_TEXTOCOMPL ETO.pdf. Acesso em: 310ut. 2020.

PRIGOGINI, Ilya; STENGERS, Isabelle. A nova aliança: metamorfose da ciência. Brasília: Editora Universidade de Brasília, 1991.

SANTOS, Milton, A natureza do espaço: técnica e tempo, razão e emoção. São Paulo:

Editora da Universidade de São Paulo, 2006. 
SANTOS, Bernardo Tavares dos. Metafísica e exterioridade: Jean Wahl e o gosto empirista de Deleuze. 2017. 105 f. Dissertação (Mestrado em Filosofia) - Universidade de Brasília, Brasília, 2017.

SEDREZ, Maycon Ricardo. A contribuição da arquitetura fractal para o ensino de CAAD. Oculum Ensaios, Campinas, v.11-12, p. 44-57, jan./dez. 2010.

SILVA, Luiz Fernando Villares E. (org.). Coletânea da legislação indigenista brasileira. Brasília: CGDTI/FUNAI, 2008. 818p .

SIQUEIRA, Rodrigo. Introdução aos fractais. In: Siqueira, Rodrigo. Grupo Fractarte. São Paulo, 18 abr. 2005. Disponível em: http://www.insite.com.br/fractarte/artigos.php. Acesso em: 07 out. 2020.

SOLER, Andre da, SANTOS, Fernanda Andrade dos. Multiescalaridade urbana: questões de escala nos estudos e políticas urbanas. In: ENCONTRO NACIONAL DA ASSOCIAÇÃO NACIONAL DE PÓS-GRADUAÇÃO E PESQUISA EM PLANEJAMENTO URBANO E REGIONAL, 18., 2019, Natal. Anais XVIII ENANPUR 2019. Natal: [UFRN], 2019. p. 1-14.

SOUZA, Lauriene Seraguza Olegário et al. Cosmos, corpos e mulheres kaiowá e guarani de anã à kuña. 2013. Dissertação (Mestrado em Antropologia) - Programa de Pós-Graduação em Antropologia, Universidade Federal da Grande Dourados, Dourados, 2013. Disponível em:

http://repositorio.ufgd.edu.br/jspui/bitstream/prefix/116/1/LaurieneSeraguzaOlegarioeSou za.pdf. Acesso em: 5 mar. 2021.

SOUZA, Marcela Stockler Coelho de. Contradisciplina: indígenas na pós-graduação e os futuros da antropologia. Revista De Antropologia, São Paulo, v. 60, n.1, p.99-116, 2017.

STENGERS, Isabelle. L'Invention des sciences modernes. Paris: La Découverte, 1993.

TEMPESTA, Giovana Acácia; FERREIRA, Igor Nicolau R.; NOLETO, Juliana A. (orgs.) Orientações básicas para a caracterização ambiental de terras indígenas em estudo: leitura recomendada para todos os membros do grupo técnico. Brasília: Funai/GIZ. 2013.

WAGNER, Roy. A pessoa fractal. Ponto Urbe, São Paulo, n. 08, p. 1-14, 2011. 
Recebido em: 03/11/2020 Aprovado em: 31/03/2021

Universidade do Estado de Santa Catarina - UDESC

Centro de Ciências Humanas e da Educação - FAED

PerCursos

Volume 22 - Número 48 - Ano 2021 revistapercursos@gmail.com 